\title{
A Case of Downhill Esophageal Varices associated with Superior Vena Cava Syndrome due to Mediastinal Mass
}

Bulent Colak, Harun Erda, Mehmet Arhan, Mehmet Ibis, Selahattin Unal

\section{ABSTRACT}

Here we report a case of downhill esophageal varices who complained of weight loss, abdominal pain after meals, fatigue, anorexia, dizziness and swollen face for 2 months.

Abbreviation: SVC: Superior vena cava.

Keywrods: Downhill esophageal varice, Superior venacava syndrome, Mediastinal mass.

How to cite this article: Colak B, Erda $H$, Arhan M, Ibis $M$, Unal S. A Case of Downhill Esophageal Varices associated with Superior Vena Cava Syndrome due to Mediastinal Mass. Euroasian J Hepato-Gastroenterol 2012;2(2):107-108.

Source of support: Nil

Conflict of interest: None

\section{INTRODUCTION}

Downhill esophageal varices have been described by Israelski and Simchowitz in 1932. The term 'downhill' indicates direction of blood flow and should be distinguished from conventional 'uphill' varices; those are due to portal hypertension. Various cases of downhill varices have been reported from 1932 till now. ${ }^{1}$ Isolated proximal esophageal varices (downhill varices) usually develop from obstruction or compression of superior vena cava (SVC). Various benign or malignant causes are known. ${ }^{1,2}$ 'Downhill' varices are usually seen with SVC syndrome and is due to mass effect of lung cancers, intrathoracic goiter, mediastinal lymphoma, thyroid carcinoma, thymoma, mediastinal lymphadenopathy secondary to different head, and neck cancers, such as carcinoma of the tongue. ${ }^{2}$ Behcet's disease, systemic venulitis, thyroid disease or a history of thyroid surgery, fibrosing mediastinitis, as a complication of upper extremity hemodialysis access, Castleman's disease (angiofollicular lymph node hyperplasia), muscular constriction of abnormal extensions of posterior hypopharyngeal veins and venous obstruction as a rare late complication after correction of congenital heart defect and are unusual causes of downhill esophageal varices, as interestingly, a patient with liver cirrhosis have also been reported. ${ }^{2-4}$ Downhill varices were reported with up to $50 \%$ with mediastinal pathologies. ${ }^{5}$ In downhill varices, bleeding is very rare complication and does not require endoscopic teatment. ${ }^{6}$ In case of bleeding, endoscopic band ligation or angiographic treatment with systemic embolization through brachiocephalic vein and sclerosing agents injection is recommended. ${ }^{2,7}$

\section{CASE REPORT}

A 53-year-old male patient admitted to internal medicine outpatient service with weight loss (had lost $8 \mathrm{~kg}$ within 2 months), abdominal pain after meals, fatigue, anorexia, dizziness and swollen face in morning. His complaints had been for 2 months. There was history of $224 \mathrm{gm} /$ day alcohol consumption and 25 packs/year smoking habit for 15 years. There was no history of jaundice, hepatitis and familial liver disease. In the laboratory investigation, the findings were as follows: hemoglobulin: $14.86 \mathrm{gm} / \mathrm{dl}$, white blood cell: $8300 / \mathrm{mm}^{3}$, platelet counts: $162000 / \mathrm{mm}^{3}$. The levels of aspartate aminotrasnferase, $23 \mathrm{IU} /$; alanine aminotransferase, 21 IU/l; gamma-glutamyl transpeptidase, 27 IU/l; total bilirubin: $0.93 \mathrm{mg} / \mathrm{dl}$; alpha-fetoprotein, $1.3 \mathrm{ng} / \mathrm{ml}$; calcium, 19-9: $5.76 \mathrm{U} / \mathrm{ml}$; ferritin, $60.9 \mathrm{ng} / \mathrm{ml}$; transferrin saturation $25 \%$ were within normal range. The patient was negative for hepatitis B surface antigen and antibody to hepatitis C virus but expressed antibody to hepatitis B surface antigen. Prothormbin time was 11.5 seconds and albumin level was $4.2 \mathrm{gm} / \mathrm{dl}$. The levels of ceruloplasmin and alpha- 1 antitrypsin were 31.5 and $201 \mathrm{mg} / \mathrm{dl}$ respectively. Endoscopic examination was performed due to symptom of dyspepsia. Upper gastrointestinal endoscopy revealed proximal esophageal varices (Fig. 1). Distal esophagus, stomach and duodenum had normal appearance. At the physical examination, superficial venous collaterals were obtained in upper extremity and thorax, thought to superior vena cava (SVC) syndrome.

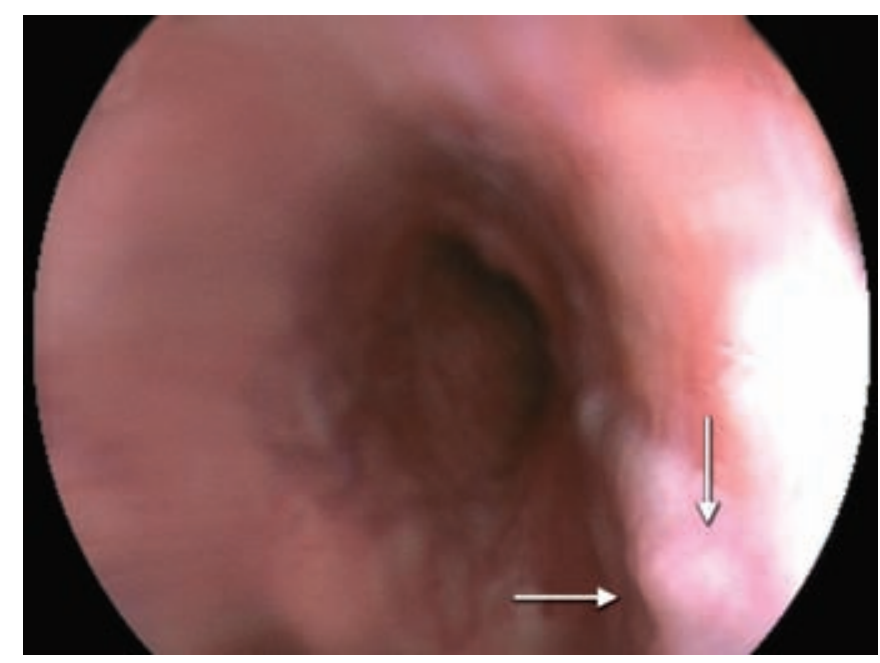

Fig. 1: Endoscopic view of proximal esophagus varices 


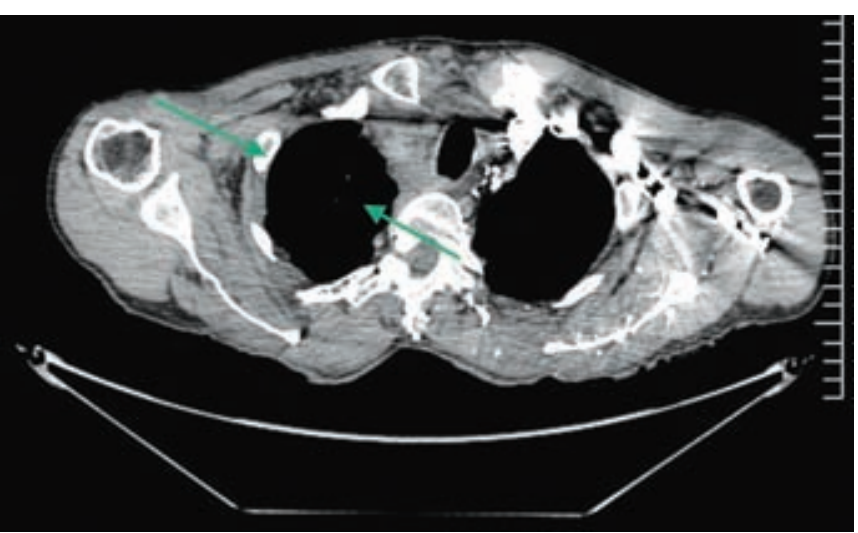

Fig. 2: Angiographic view of mediastinal mass and collaterals around the esophagus

Computed tomographic angiography revealed $59 \times 47$ $\times 80 \mathrm{~mm}$ mass at right anterior mediastnum, also left brachiocephalic vein and SVC were not visualized, which may be due to thrombosis (Fig. 2). Azygos veins were dilated. Mediastenal and paravertebral venous collaterals were seen. Collateral venous structure was seen in anterior abdomenal wall and anterior part of the liver. Inferior vena cava has been filled with azygos vein. Portal vein was normal with Doppler ultrasonography. Mediastinoscopy was performed. Histopathologic examination of specimen revealed poorly differentiated carcinoma, squamous cell carcinoma.

\section{REFERENCES}

1. Ibis M, Ucar E, Ertugrul I, Boyvat F, et al. Inferior thyroid artery embolization for downhill varices caused by a goiter. Gastrointest Endosc 2007;65:543-45.

2. Tavakkoli H, Asadi M, Haghighi M, Esmaeili A. Therapeutic approach to 'downhill' esophageal varices bleeding due to superior vena cava syndrome in Behcet's disease: A case report. BMC Gastroenterol 2006;6:43.

3. Tincani E, Criscuolo C, Zenesini A, Bondi M. An unusual site of bleeding from esophageal varices. Recenti Prog Med 1998;89:301-03.
4. Basaranoglu M, Ozdemir S, Celik AF, Senturk H, Akin P. A case of fibrosing mediastinitis with obstruction of superior vena cava and downhill esophageal varices: A rare cause of upper gastrointestinal hemorrhage. J Clin Gastroenterol 1999;28: 268-70.

5. Mönkemüller K, Poppen D, Feldmann K, Ulbricht LJ. Downhill varices resulting from giant intrathoracic goiter. Endoscopy 2010;42(suppls):E40.

6. Savoy AD, Wolfsen HC, Paz-Fumagalli R, Raimondo M. Endoscopic therapy for bleeding proximal esophageal varices: A case report. Gastrointest Endosc 2004;59:310-13.

7. Tsokos M, Bartel A, Schoel R, et al. Fatal pulmonary embolism after endoscopic embolization of downhill esophageal varix. Dtsch Med Wochenschr 1998;123:691-95.

\section{ABOUT THE AUTHORS}

\section{Bulent Colak}

Faculty of Medicine, Department of Gastroenterology, Gazi Hospital Gazi University, Ankara, Turkey

Correspondence Address: Naci Cakir Mah. Sinan Cad. 42/3, Dikmen, Ankara, Turkey, Phone: 003124810501, e-mail: colakb1976@yahoo.com

\section{Harun Erda}

Faculty of Medicine, Department of Gastroenterology, Gazi Hospital Gazi University, Ankara, Turkey

\section{Mehmet Arhan}

Faculty of Medicine, Department of Gastroenterology, Gazi Hospital Gazi University, Ankara, Turkey

\section{Mehmet lbis}

Faculty of Medicine, Department of Gastroenterology, Gazi Hospital Gazi University, Ankara, Turkey

\section{Selahattin Unal}

Faculty of Medicine, Department of Gastroenterology, Gazi Hospital Gazi University, Ankara, Turkey 